\title{
(t)
}

\section{ESTRATÉGIAS E TÁTICAS NA FORMAÇÃO PROFISSIONAL DO ASSISTENTE SOCIAL: SUBSÍDIOS PARA REFLEXÃO}

\author{
Strategies and tactics in professional training for the social worker: reflection grants \\ Luciana Gonçalves Pereira de Paula* \\ Nicole Cristina Oliveira Silva**
}

\begin{abstract}
RESUMO
O presente artigo traz reflexões sobre o debate em torno das estratégias e táticas no Serviço Social, abordando, especificamente, o trato desses elementos no âmbito da formação profissional. Para isso, realiza um breve resgate da produção de conhecimento sobre essa temática, em nossa área. Traz ponderações acerca da abordagem desses elementos nos projetos pedagógicos dos cursos de Serviço Social. Por fim, apresenta resultados parciais de uma pesquisa empírica, de caráter qualitativo, realizada junto aos/às alunos/as formandos/as da FSS/UFJF. Entre as conclusões, destacamos a importância de se garantir, na esfera da graduação em Serviço Social, espaço para os debates em torno da construção das estratégias e táticas profissionais, como forma de qualificar a atuação dos futuros assistentes sociais.
\end{abstract}

\section{PALAVRAS-CHAVE}

Serviço Social; Assistente Social; Formação profissional; Estratégias e táticas.

\begin{abstract}
This article presents reflections on the debate about strategies and tactics in Social Work, specifically addressing the treatment of these elements in the scope of vocational training. To do so, it performs a brief rescue of the production of knowledge about this subject in our area. It brings up considerations about the approach of these elements in the pedagogical projects of the courses of Social Work. Finally, it presents partial results of an empirical research, of qualitative character, performed with the students / trainees of the FSS / UFJF. Among the conclusions, we emphasize the importance of ensuring, in the sphere of graduation in Social Work, space for debates about the construction of professional strategies and tactics, as a way of qualifying the work of future social workers.
\end{abstract}

\section{KEYWORDS}

Social Work; Social worker; Professional qualification; Strategies and tactics.

Submetido em: 30/3/2019.

Aceito em: 16/9/2019.

\footnotetext{
* Assistente social. Doutora em Serviço Social. Professora Adjunta na Faculdade de Serviço Social da Universidade Federal de Juiz de Fora. (UFJF, Juiz de Fora, Brasil). Campus Universitário, Rua José Lourenço Kelmer, s/n - São Pedro, Juiz de Fora - MG, 36036-900. ORC ID: <https://orcid.org/0000-0002-6744-4234>. Email: <lugppaula@gmail.com>.

** Assistente social. Mestra em Serviço Social. Professora Substituta na Faculdade de Serviço Social da Universidade Federal de Juiz de Fora. (UFJF, Juiz de Fora, Brasil). Campus Universitário, Rua José Lourenço Kelmer, s/n - São Pedro, Juiz de Fora - MG, 36036-900. ORC ID: <https://orcid.org/0000-0001-8595-7116>. Email: <nicolecosilva19@gmail.com>.
}

\section{DOI 10.22422/temporalis.2019v19n37p189-205}

(cc) Br Commons Atribuição 4.0 Internacional (https://creativecommons.org/licenses/by/4.o/deed.pt_BR), que permite copiar e redistribuir o material em qualquer suporte ou formato, bem como adaptar, transformar e criar a partir deste material para qualquer fim, mesmo que comercial. O licenciante não pode revogar estes direitos desde que você respeite os termos da licença.

Temporalis, Brasília (DF), ano 19, n. 37, p. 188-204, jan./jun. 2019. | ISSN 2238-1856 


\section{INTRODUÇÃO}

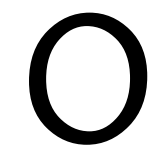
debate teórico em torno dos termos "estratégia" e "tática" não é recente em nossa sociedade. É de longa data a tentativa de conceituar tais termos e definir a relação existente entre eles. Segundo Bogo (2008), esses termos - estratégia e tática -, para além de suas definições semânticas, vêm sendo preenchidos, ao longo da história, com diferenciados conteúdos e significados.

No campo de Serviço Social, embora esses termos venham aparecendo, com cada vez mais frequência, em livros e artigos publicados na área, a sua menção raramente vem acompanhada de uma conceituação.

Diante da complexidade e das exigências colocadas para nossa categoria, em tempos de adensamento da crise capitalista, sua discussão se faz necessária para a profissão, devendo abranger o âmbito da formação acadêmica e do trabalho profissional.

No que se refere à esfera da formação, ainda temos pouco conhecimento sobre o modo como este tema tem sido discutido com os/as discentes de Serviço Social no rol de disciplinas e conteúdos que as compõe. Diante disso, propomo-nos neste artigo a apresentar as reflexões de alguns de nossos/as alunos/as acerca destes conceitos, afim de apontar possibilidades para a qualificação do debate na academia e, consequentemente, do próprio processo de formação dos/as profissionais.

As reflexões aqui apresentadas constituem resultados parciais da pesquisa intitulada $A$ formulação das estratégias político-profissionais e das táticas técnico-operacionais - reflexões sobre formação e trabalho profissional do assistente social, realizada no Grupo de Estudos e Pesquisas dos Fundamentos do Serviço Social (GEPEFSS) na Faculdade de Serviço Social da Universidade Federal de Juiz de Fora (FSS/UFJF). Essa pesquisa integrou o Plano de Estágio Pós-doutoral de uma das autoras, realizado no Programa de Pós-Graduação em Serviço Social da Universidade Federal do Rio de Janeiro.

Através de uma pesquisa empírica, de caráter qualitativo, foram realizadas entrevistas estruturadas com alunos/as formandos/as (alunos/as do oitavo período diurno e do nono período noturno) da FSS/UFJF, no período de agosto a dezembro dos anos de 2016, 2017 e 2018 (segundo semestre letivo da UFJF). Parte dos resultados obtidos com essa pesquisa, particularmente no que tange ao tema das estratégias e táticas profissionais, serão o escopo desse artigo.

Com isso, almejamos contribuir para o aprofundamento e para a qualificação da discussão em torno das estratégias e táticas no campo do Serviço Social, bem como refletir sobre o processo de ensino-aprendizagem dessa temática no âmbito da formação profissional.

\section{A FORMAÇÃO PROFISSIONAL EM SERVIÇO SOCIAL PARA ALÉM DO PRAGMATISMO EXIGIDO PELO MERCADO DE TRABALHO}

Toda e qualquer formação acadêmica de ensino superior tem como finalidade a preparação de profissionais qualificados para atuar no mercado de trabalho, desenvolvendo atribuições e competências especificas a cada profissão, premissa que se coloca também ao Serviço Social.

Temporalis, Brasília (DF), ano 19, n. 37, p. 188-204, jan./jun. 2019. | ISSN 2238-1856 


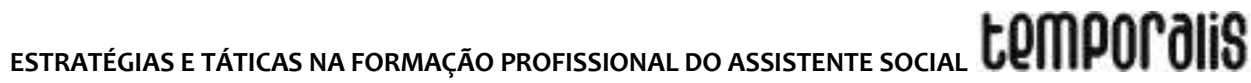

Contudo, no campo do Serviço Social, compreendemos que a formação profissional

[...] não se reduz à oferta de disciplinas que propiciem uma titulação ao Assistente Social para responder a uma condição para sua inserção no mercado de trabalho. Se este é um elemento presente no processo de formação, ele o extrapola: tratase de preparar cientificamente quadros profissionais capazes de responder às exigências de um projeto profissional coletivamente construído e historicamente situado (IAMAMOTO, 1992, p. 162-163).

O que se evidencia com isso é que a formação profissional em Serviço Social, embora atenda às demandas do mercado de trabalho - e não há possibilidade de se desobrigar disto, posto que se justifica nesta finalidade -, deve transpor à tendência pragmática dessa esfera ao preparar os/as profissionais para construir respostas às demandas e requisições que Ihes chegam, amparados nos princípios contidos em nosso projeto profissional hegemônico.

Ao assumir esta função, coloca-se para a formação profissional a necessidade de preparar os/as discentes para que leiam a realidade em uma perspectiva de totalidade, buscando desvelar seus meandros e contradições, ao mesmo tempo em que se qualifiquem para responder, enquanto assistentes sociais, às requisições institucionais, às exigências do mercado de trabalho, mas, especialmente, às reais necessidades/demandas dos/as seus/suas usuários/as. Por essa razão, segundo lamamoto (1992), "[...] a preparação para a profissão não pode ser confundida com a preparação para o emprego [...]” (IAMAMOTO, 1992, p. 164), visto que ela se articula às demandas reais do cotidiano que, em termos de complexidade, exigem maior conhecimento e competência por parte dos/das assistentes sociais.

As premissas desse projeto de formação que transpõe o mero preparo para o emprego, encontram-se nas diretrizes curriculares para a graduação em Serviço Social elaboradas pela Associação Brasileira de Ensino e Pesquisa em Serviço Social (ABEPSS), no ano de 1996. Esse documento defende um projeto de formação profissional que aposta nas lutas sociais e no acúmulo de forças necessárias à transformação da ordem capitalista vigente. "Construção essa que é processual, que está sendo realizada na cotidianidade da prática social, cabendo aos agentes profissionais detectá-las e delas partilhar, contribuindo, como cidadãos e profissionais, para o seu desenvolvimento" (IAMAMOTO, 2001, p. 195).

Desse modo, o processo de formação profissional precisa ser capaz de estimular nos/nas discentes - futuros/as assistentes sociais - uma aproximação com as reais condições de vida da classe trabalhadora, o que envolve aproximar-se de suas formas de viver, sobreviver, resistir e se revoltar frente aos constantes ataques que se colocam na atual conjuntura (IAMAMOTO, 2001). Essas lutas manifestam-se nos espaços coletivos politicamente organizados, mas também estão presentes no cotidiano de vida dos sujeitos com os quais o/a assistente social trabalha, cabendo ao/à profissional detectar esses focos de resistência para estimular a mobilização/organização dos trabalhadores.

Assim sendo, a formação profissional deve oferecer aos/às futuros/as assistentes sociais o suporte teórico-metodológico necessário ao desvelamento da realidade e ao estabelecimento de estratégias de ação. Segundo lamamoto (1992), "[...] isso implica uma especial atenção aos recursos técnico-operativos na efetivação de estratégias de atuação

Temporalis, Brasília (DF), ano 19, n. 37, p. 188-204, jan./jun. 2019. | ISSN 2238-1856 
voltadas para os setores majoritários da população" (IAMAMOTO, 1992, p. 165). Diante de tal assertiva, faz-se necessário apresentar algumas considerações sobre o debate em torno da construção dessas estratégias profissionais.

\section{O DEBATE SOBRE ESTRATÉGIAS E TÁTICAS NO SERVIÇO SOCIAL: APONTAMENTOS SOBRE A PRODUÇÃO NESSA ÁREA DE CONHECIMENTO}

Como mencionamos na introdução desse artigo, nos últimos anos, temos constatado um aumento no número de obras publicadas, no âmbito de nossa profissão, que trata, de algum modo, de estratégias e táticas. Com alguma frequência encontramos a utilização desses termos - especialmente "estratégia" - nos títulos de alguns livros recentemente lançados. " Entretanto, cabe destacar que essas obras apresentam o termo "estratégia", mas não realizam um debate acerca da sua caracterização, da sua conceituação.

Em um levantamento realizado junto a produções teóricas um pouco mais antigas, no campo do Serviço Social ${ }^{2}$ - especialmente aquelas publicadas a partir da década de $1980^{3}$ -, pudemos constatar que o debate construído sobre o tema das estratégias e táticas apresenta-se sob diferentes perspectivas metodológicas.

As décadas de 1980 e 1990 apresentam-se como o momento mais fértil para os debates em torno das estratégias e táticas no Serviço Social. Nesses decênios, identificamos produções que construíram reflexões significativas acerca dessa temática. No presente artigo destacaremos: Faleiros (1985 e 1997), Netto (1986) e lamamoto (1992).

Segundo Faleiros (1985), dentro das instituições, os/as profissionais do Serviço Social podem desenvolver diferentes estratégias profissionais na condução de sua atuação. Essas estratégias, por sua vez, podem objetivar a transformação das correlações de forças institucionais, através da formação de alianças entre os técnicos, os profissionais e o público alvo destes espaços de atuação.

Encontramos em Faleiros (1985) uma indicação estratégica interessante. O autor aponta para o/a assistente social a possibilidade de, por meio de uma análise institucional, identificar aliados e construir frentes de trabalho coletivas que visem alterações nas correlações de força. Ressalta, ainda, que esse processo vai depender das reais condições objetivas em que se encontra o/a assistente social dentro das instituições. Com base nessas reflexões, o autor apresenta a sua compreensão em torno dos termos estratégia e tática:

A estratégia e a tática não são o resultado de uma opção. A gente não faz a guerra conforme quer. Elas são o resultado de forças em presença, de recursos disponíveis, e 'mobilizáveis', e de interesses e objetivos a atingir num momento

\footnotetext{
${ }^{1}$ Como exemplo podemos destacar: KERN, Francisco Arseli. As mediações em redes como estratégia metodológica do Serviço Social; MOREIRA, Carlos Felipe Nunes. O Trabalho com Grupos no Serviço Social - a dinâmica de grupo como estratégia para reflexão crítica; OLIVEIRA, Edson Marques. erviço Social e Sustentabilidade Humana - o empreendedorismo social como estratégia de direitos; entre outras.

${ }^{2}$ Esse levantamento foi inicialmente realizado no ano de 2013, para o processo de construção da tese de doutorado intitulada Um debate sobre estratégias e táticas - problematizações no campo do Serviço Social, defendida em 2014, no Programa de Pós-Graduação em Serviço Social da Universidade Federal do Rio de Janeiro. Para a elaboração do presente artigo esse levantamento foi retomado e atualizado, no ano de 2017. 3 Tomamos como recorte histórico para o nosso levantamento a década de 1980, por ser a época em que se inicia, no Serviço Social, uma aproximação mais madura com os debates realizados pela Tradição Marxista, o que se reflete em muitas publicações que começam a expressar teoricamente os elementos apresentados pela intenção de ruptura no Processo de Renovação do Serviço Social brasileiro.
}

Temporalis, Brasília (DF), ano 19, n. 37, p. 188-204, jan./jun. 2019. | ISSN 2238-1856 


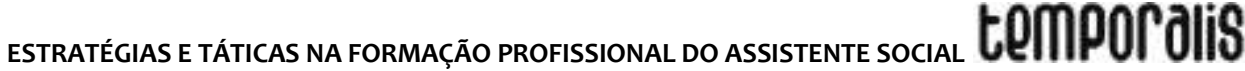

dado. A estratégia se refere aos objetivos a atingir num período mais longo da história e mais geral. A tática se refere a objetivos particulares num período mais curto e subordinados à estratégia (FALEIROS, 1985, p. 81).

Os elementos aqui destacados compõem para Faleiros a base da sua "teoria do fortalecimento" que será apresentada de maneira mais clara na obra de 1997. Segundo o autor, o/a assistente social estaria, dessa forma, construindo estratégias de fortalecimento dos seus usuários e não apenas servindo às estratégias dominantes como mecanismo utilizado para o seu enfraquecimento.

Em Faleiros (1997), a abordagem da estratégia se vincula ao debate do empoderamento, visto que a classifica como possibilidade que surge em meio às contradições e dificuldades existentes na correlação de forças e que pode favorecer "[...] o processo e o projeto de vida do sujeito, no sentido de buscar o que ele quer e pode construir a partir das forças de que dispõe [...]" (FALEIROS, 1997, p. 59).

Defendendo a utilização do empowerment ${ }^{4}$ como estratégia para o Serviço Social, o autor em questão está indicando a realização de um trabalho com foco nos indivíduos sociais para que eles possam realizar mudanças comportamentais que os levem a uma mudança em suas trajetórias de vida. Na análise do autor, as relações de poder perpassam o cotidiano dos indivíduos e, por isso, a intervenção profissional do/da assistente social deve voltar-se para o fortalecimento do poder de seus usuários que se encontram, na maioria das vezes, fragilizados. E essa postura profissional envolve "[...] a construção de estratégias para dispor de recursos, poder, agilidade, acesso, organização, informação, comunicação" (FALEIROS, 1997, p. 41).

Segundo Faleiros (1997), o saber e o poder da informação são capazes de fortalecer os indivíduos, constituindo-se num primeiro passo para o empoderamento. Desse modo, percebemos que a abordagem do autor não aponta para a necessidade de transformação das estruturas sociais, mas para a mudança de postura dos indivíduos considerados oprimidos para que eles próprios possam romper com a sua condição de opressão.

No entanto, essa é também a concepção de empowerment que prevalece hoje no campo das políticas sociais nacionais, bem como da União Europeia e nas Declarações de princípios e de ações internacionais (PINTO, 2011). Nessas políticas e documentos o empowerment tem aparecido como estratégia de combate à pobreza, como instrumento de mobilização dos indivíduos nos processos de inclusão social. Com isso, a intenção é aumentar o poder das pessoas para que possam reforçar suas próprias capacidades.

De acordo com Paula (2014), as reflexões de Faleiros (1997) incorporam-se ao "[...] rol das teorias que pretendem superar as supostas limitações das abordagens marxistas" (PAULA, 2014, p. 413). Supostas, pois, consideramos que é a tradição marxista que fornece os elementos para pensar o debate das estratégias de modo mais qualificado, conforme perceptível em Netto (1986) e em lamamoto (1992).

\footnotetext{
${ }^{4}$ O termo empowerment utilizado por Faleiros (1997), em sua tradução literal, significa "empoderamento" e possui em seu núcleo central a partícula "poder". No entanto, esse termo possui um vasto leque de significados, definições e interpretações, possuindo, assim, um caráter profundamente polissêmico.
} 
Em Netto (1986), as estratégias de intervenção não podem ser pensadas como método ou modelo de atuação, pois o Serviço Social não possui metodologia própria, da mesma forma que não possui uma teoria própria. Segundo o autor,

[...] a teoria social não é uma matéria, uma disciplina ou uma ciência específica; ela concerne à compreensão da totalidade social, dessa totalidade em movimento que supõe objetividade, indivíduo, cultura, sociedade, economia, constituindo a substância da história (NETTO, 1986, p. 52).

Por isso, Netto (1986) afirma categoricamente que "[...] nós não temos uma teoria do Serviço Social" (NETTO, 1986, p. 50). Desse modo, o autor aponta que a teoria não pode ser confundida com qualquer "sistematização abstrata da prática". Em seus grifos, tem-se que "[...] a sistematização da prática é mais do que necessária para que ela não se reitere aleatoriamente, mas isso não é teoria” (NETTO, 1986, p. 55).

Do mesmo modo, Netto (1986) sinaliza para a confusão - muito presente no Serviço Social na década de 1980 - entre método e estratégia de intervenção. Segundo o autor, os/as assistentes sociais podem até escolher as suas estratégias de ação, mas isso não é método. Nesse sentido, as estratégias de intervenção são compreendidas como:

[...] um conjunto de procedimentos prático-empíricos, prático-imediatos, implementados para atingir determinados resultados. E é evidente que aí há um elenco a escolher, e o profissional é tanto mais competente quanto mais controla esse elenco sobre o qual ele pode optar. Porém, isto não é metodologia (NETTO, 1986, p. 56).

Corroborando com Netto (1986), outra autora que nos oferece significativas contribuições ao debate das estratégias e táticas é lamamoto (1992). Em sua obra, destaca uma necessária distinção entre "[...] concepções teórico-metodológicas e as estratégias, técnicas e procedimentos da intervenção profissional” (IAMAMOTO, 1992, p. 173). Na concepção da autora, as estratégias de atuação profissional são elementos imprescindíveis para a construção do trabalho do/da assistente social, mas não devem receber estatuto de "metodologia". Segundo lamamoto (1992), é a partir de um determinado referencial teórico-metodológico que se constroem as estratégias de ação para a realização do fazer profissional. Mas, essas estratégias não se configuram enquanto metodologias específicas do Serviço Social.

O debate formulado e apresentado por lamamoto (1992, p. 172) possui por objetivo realizar uma crítica à dicotomia entre "metodologia do conhecimento" e "metodologia da ação" distinção entre as grandes correntes do pensamento social e a dimensão da ação profissional que exigiria uma "metodologia específica". Essa tendência esteve presente nos debates da categoria, ao longo dos anos de 1980, levando segmentos profissionais a defenderem a existência de uma "metodologia do Serviço Social".

Para lamamoto (1992), a metodologia constitui uma forma de conhecimento da realidade. É o caminho que se escolhe para a compreensão do ser social historicamente dado. E, desta forma, é a metodologia que vai orientar a intervenção profissional do/da assistente social na vida social. No entanto, ela não se confunde com essa intervenção, nem se conforma enquanto estratégia, compreendida como "metodologia de ação". 


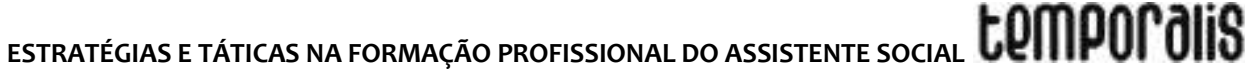

Na compreensão de lamamoto (1992) a perspectiva teórico-metodológica - e aqui estamos falando do campo marxista - possui a capacidade de revelar as possibilidades de ação, campo onde devem ser construídas as estratégias de atuação profissional.

Nesse sentido, partindo de um referencial teórico-metodológico marxista que deseja não apenas compreender a realidade, mas, especialmente, intervir sobre ela, provocando alterações, o/a assistente social deve se fazer competente. E isso implica o desenvolvimento de

[...] uma competência estratégica e técnica (ou técnico-política) que não reifica o saber fazer, subordinando-o à direção do fazer, recusando os espontaneísmos, os voluntarismos, os determinismos e demais "ismos" que cindem o exercício profissional, desviando as rotas desejáveis da ação. Em outros termos, é preciso estabelecer os rumos e estratégias de ação a partir da elucidação das tendências presentes no movimento da própria realidade, decifrando suas manifestações particulares no campo sobre o qual incide a intervenção profissional. Uma vez decifradas, essas tendências podem ser acionadas pela vontade política dos sujeitos, de forma a extrair estratégias de ação reconciliadas com a realidade objetiva, de modo a preservar sua viabilidade, reduzindo assim a distância entre o desejável e o possível (IAMAMOTO, 1992, p. 184-185).

E, finalizando suas reflexões, lamamoto (1992) destaca a importância de se desenvolver mais estudos e pesquisas sobre a construção das estratégias e táticas de ação profissional, como caminhos relevantes para o enfrentamento dos desafios postos pelo cotidiano.

\section{REFLEXÕES SOBRE ESTRATÉGIAS E TÁTICAS NO ÂMBITO DA FORMAÇÃO PROFISSIONAL DO ASSISTENTE SOCIAL: AVANÇOS E LACUNAS}

Apesar do fecundo debate acerca das estratégias e táticas, brevemente recuperado em nosso artigo, percebemos que essa discussão sofre um refluxo no século XXI, permanecendo subsumida nos últimos anos.

Em lamamoto (1992), encontramos a indicação de que as estratégias e táticas devem se construir articuladas aos propósitos e objetivos profissionais do/da assistente social. Nesse mesmo sentido, Paula (2014) sinaliza a importância de pensarmos as estratégias como elementos necessários ao alcance de determinado objetivo profissional. A partir do instante em que estabelecemos alguma finalidade, é preciso saber o que fazer para que ela seja alcançada - o que evidencia a necessidade de um bom planejamento - considerando não só as dificuldades, mas também as possibilidades que se colocam na realidade o que, em linhas gerais, consiste na definição de estratégia.

Não obstante, não basta saber o que fazer, é também necessário buscar mecanismos para colocar em prática o que se pretende, e nisso consistem as táticas, que se vinculam de modo mais imbricado à dimensão técnico-operativa da profissão, embora não se furtem, no momento de escolha do/da profissional sobre como operacionalizar determinada estratégia, de um direcionamento teórico-metodológico e ético-político.

As estratégias e táticas podem qualificar o exercício profissional do/da assistente social na medida em que possibilitam a construção de uma intervenção pautada em um

Temporalis, Brasília (DF), ano 19, n. 37, p. 188-204, jan./jun. 2019. | ISSN 2238-1856 
determinado objetivo profissional. São, portanto, ferramentas importantes a serem trabalhadas no processo de formação acadêmica de futuros/as assistentes sociais (PAULA, 2016).

Com base nisto, retomando o debate de lamamoto (1992) sobre a formulação de estratégias que preparem os/as assistentes sociais não somente para o mercado de trabalho, mas para um exercício profissional referenciado em um projeto crítico de profissão, consideramos o momento da formação como espaço privilegiado para tal. A formação em Serviço Social é lócus propício para o exercício da reflexão sobre a realidade e sobre as possibilidades de intervenção que se abrem para o conjunto da categoria, e que podem se alinhar aos valores e princípios que defendemos hegemonicamente.

Sendo a defesa do projeto ético-político crítico do Serviço Social um dos objetivos de nossa categoria - presente, de modo hegemônico, no direcionamento de nossas entidades representativas -, pensar o conjunto de estratégias e táticas que possam expressar alguns de seus princípios, no cotidiano profissional do/da assistente social, deve ser papel da formação acadêmica.

Nesse sentido, a presença deste debate não pode ser negligenciada no currículo da graduação em Serviço Social, devendo ser conteúdo das disciplinas que a compõe, principalmente

Nas ementas que se ocupam, mais especificamente, de uma reflexão teóricoprática acerca do exercício profissional, em espaços como: as supervisões acadêmicas de estágio, as oficinas teórico-práticas ou laboratórios, e ainda outros que se debruçam sobre as questões relativas à pesquisa, ao planejamento de ações, à construção de projetos de intervenção, entre outras (PAULA, 2016, p. 178).

A formação profissional do/da assistente social, ao longo das décadas de 1980 e 1990 pautada na reforma curricular de 1982 - registrou maiores avanços no campo teóricometodológico, buscando oferecer aos/às discentes um arcabouço mais consistente para melhor desvelar a realidade. Contudo, o chamado "ensino da prática" esteve relegado ao um segundo plano até 1996, quando as diretrizes curriculares da ABEPSS passaram a lhe conferir lugar de maior destaque.

Partindo do pressuposto de que a formação profissional precisa estar ancorada não só em uma consistente fundamentação teórico-metodológica, mas também técnico-instrumental, o desafio posto é oferecer reflexões sobre

[...] a mediação entre o ‘ensino teórico' e o ‘ensino da prática', para que o discente se aproprie de um instrumental de análise e, pela apreensão crítica de situações singulares, possa compreender a particularidade de seu objeto de investigação e intervenção (IAMAMOTO, 2001, p. 269).

Desse modo, a atual proposta da ABEPSS, que oferece subsídio para a formação profissional, estrutura-se sobre três núcleos de fundamentação complementares, a saber: núcleo de fundamentos teórico-metodológicos da vida social; núcleo de fundamentos da formação sócio-histórica da sociedade brasileira; núcleo de fundamentos do trabalho profissional. 


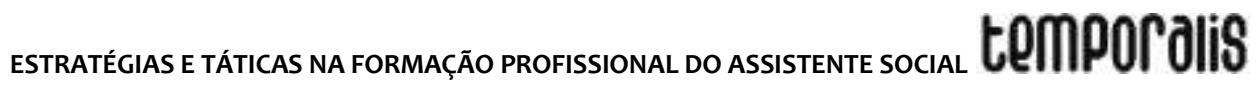

No que compete ao ensino teórico prático, grandes avanços são registrados nessa proposta, como a possibilidade de criação de disciplinas denominadas oficinas e laboratórios de intervenção profissional. Em se tratando das oficinas, especialmente, das chamadas Oficinas de Prática, identificamos na proposta construída pela FSS/UFJF - e apresentada por lamamoto (2001) - uma excepcional inovação.

\begin{abstract}
As oficinas de prática, conduzidas por um professor de Serviço Social, são instâncias que propiciam, desde o ingresso do aluno na Universidade, a aproximação do discente à realidade social e profissional, além de estimular o seu envolvimento na dinâmica da vida universitária. Oferecem um conjunto de informações e experiências sociais, artísticas e culturais, que possam ampliar o acesso, por parte do estudante, ao patrimônio científico, artístico e cultural acumulado, contribuindo para a formação do cidadão universitário. Objetivam ainda desenvolver a capacidade crítica diante das múltiplas expressões da questão social (IAMAMOTO, 2001, p. 287).
\end{abstract}

Assim, as Oficinas de Prática deveriam se constituir em disciplinas ofertadas ao longo de todo o processo formativo (desde o início até o fim da formação), tendo os seguintes focos temáticos: Oficinas I e II - a universidade, a cultura, o Serviço Social e a questão social; Oficinas III e IV - a investigação e a observação do trabalho profissional. Iamamoto (2001) ainda destaca que

As Oficinas de Prática III e IV deverão ser acompanhadas das disciplinas de Ética Profissional e de Estratégias e Técnicas do Serviço Social I e II e dos Laboratórios, como parte da preparação discente para o estágio propriamente dito (IAMAMOTO, 2001, p. 289).

Com isso, verificamos que existem indicativos de criação de disciplinas de Estratégias e Técnicas no Serviço Social I e $I^{5}$, cabendo destacar que a proposta aponta para que a participação e a educação popular sejam conteúdos ministrados nessas disciplinas.

A proposta de reforma curricular da Faculdade de Serviço Social/UFJF foi implementada a partir do ano de 2003. A reforma que se efetivou constituindo-se enquanto projeto pedagógico do curso de Serviço Social apresenta diferenças em relação às indicações de lamamoto (2001).

No que tange ao ensino teórico prático consideramos um importante avanço a criação das disciplinas de Oficinas de Supervisão de Estágio - pelas quais os/as alunos/as passam ao longo dos três semestres de Estágio Supervisionado -; Oficinas de Trabalho Profissional sendo oferecidas três disciplinas de forma concomitante à realização do Estágio Supervisionado -; Laboratórios de Áreas de Intervenção - oferecidos a partir do quinto semestre do curso, em sua maioria na modalidade eletiva.

No entanto, percebemos que, atualmente, as Oficinas não são mais oferecidas ao longo de toda a formação, como indicado na proposta apresentada por lamamoto (2001). Também não foram criadas as disciplinas de Estratégias e Técnicas no Serviço Social. Atualmente as Oficinas de Trabalho Profissional cumprem, de certo modo, o que, na indicação de

\footnotetext{
5 “As disciplinas e/ou oficinas de Estratégias e Técnicas no Serviço Social propiciam momentos específicos de aprendizado e desenvolvimento de instrumentais, técnicas e habilidades, de modo que deem suporte ao estágio e à pesquisa" (IAMAMOTO, 2001, p. 289).
}

Temporalis, Brasília (DF), ano 19, n. 37, p. 188-204, jan./jun. 2019. | ISSN 2238-1856 
lamamoto (2001), estava destinado às disciplinas de Estratégias e Técnicas. Mas, destacamos que os conteúdos anteriormente destacados - e considerados por nós como fundamentais a uma formação efetivamente crítica -, como a participação e a educação popular, não se encontram, hoje, como foco central de nenhuma das disciplinas do curso de Serviço Social da UFJF, com o objetivo sinalizado pela autora.

Consideramos que o investimento em espaços coletivos, o desenvolvimento de ações que estimulem a participação, a mobilização e a organização das comunidades com as quais o/a assistente social trabalha, assim como a realização de trabalhos de educação popular, constituem-se em importantes estratégias profissionais a serem desenvolvidas no âmbito do Serviço Social.

No entanto, se esses conteúdos não estiverem alocados em algum momento específico da formação (em alguma disciplina ou conjunto de disciplinas), se não forem devidamente debatidos no espaço da academia, não podemos exigir/cobrar, posteriormente, que os/as assistentes sociais realizem ações dessa natureza.

Desse modo, buscando respaldar, de maneira ainda mais qualificada, nossa defesa quanto a necessidade de se ter um espaço assegurado para o debate das estratégias e táticas no processo de formação dos/das futuros/as assistentes sociais, realizamos uma pesquisa empírica que ouviu vinte alunos/as da FSS/UFJF - dentro de um universo de quarenta formandos/as, durante o segundo semestre letivo dos anos de $2016^{6}$. Na pesquisa adotamos, como procedimento metodológico, a entrevista estruturada, utilizando um roteiro composto por quinze questões abertas. As entrevistas foram gravadas, posteriormente transcritas e analisadas à luz do método materialista histórico dialético.

Com essa pesquisa procuramos conhecer como os/as discentes formandos/as em Serviço Social da UFJF têm compreendido as discussões realizadas nas disciplinas de caráter teórico prático. Para esse artigo, em especial, nos atemos ao debate das estratégias e táticas, procurando detectar se as disciplinas do curso as têm abordado, e de que forma os/as alunos/ estão se apropriando desses elementos.

\section{O DEBATE DAS ESTRATÉGIAS E TÁTICAS NA PERSPECTIVA DISCENTE: UMA ANÁLISE DA REALIDADE DA FACULDADE DE SERVIÇO SOCIAL/UFJF}

Realizadas pelas pesquisadoras componentes do GEPEFSS, as entrevistas com os/as discentes formandos/as da FSS/UFJF revelaram questões muito significativas em torno das disciplinas que, hoje, compõem o conjunto teórico prático do projeto pedagógico dessa unidade acadêmica.

No entanto, para o presente artigo, vamos nos ater a quatro questões que se referem: à compreensão do conceito/significado do termo estratégia; à compreensão do conceito/significado do termo tática; à existência ou não de um debate sobre estratégias e táticas no processo de formação; e às possíveis estratégias e táticas a serem construídas por esses/as discentes em sua futura atuação profissional.

\footnotetext{
${ }^{6}$ Essa coleta de dados continuou ocorrendo, sempre no segundo semestre, também nos anos de 2017 e 2018. No entanto, para esse artigo a análise se debruçou sobre as entrevistas realizadas em 2016.
} 


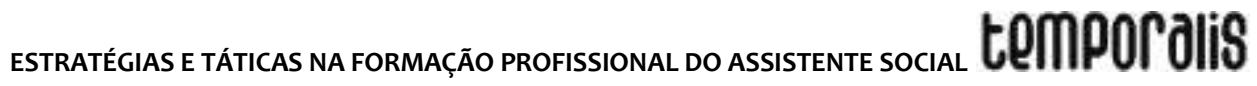

Ao serem questionados/as sobre o significado dos termos estratégia e tática, as respostas demonstraram, em certa medida, uma boa compreensão dos elementos que envolvem este debate, embora os conceitos não apareçam de modo preciso.

Em relação ao conceito de estratégia, especificamente, percebemos que os/as discentes o relacionaram às possibilidades de atuação profissional, aos objetivos profissionais, às dimensões da profissão, às respostas profissionais e à necessária construção das táticas.

Na perspectiva de dois/duas entrevistados/as as estratégias foram percebidas como possibilidades que emergem em meio às dificuldades do trabalho cotidiano, conforme as seguintes assertivas:

Eu acho que as estratégias são criadas nos momentos adversos mesmo, porque sempre vai ter limites, independente do local onde a pessoa estiver (Entrevistado/a 03).

São formas de [...] atuar com diferentes situações quando se encontra numa situação que você não tem saída. Você procura outras dentro do seu conhecimento [...] (Entrevistado/a 04).

Percebemos aqui uma compreensão mais aproximada daquela apresentada por Faleiros (2006), que sinaliza a possibilidade de construção de estratégia em meio às dificuldades e contradições. É importante salientar que a perspectiva discente não se alinha ao discurso do empoderamento nas falas apresentadas. No entanto, o fato de sinalizarem a importância da construção de estratégias apenas em momentos de dificuldade, pode ser um indício da falta de compreensão desses elementos como parte fundamental da intervenção profissional, visto que todo/a assistente social deve possuir objetivos orientadores, planos e projetos profissionais que possam lhe oferecer direção.

Em outras duas respostas obeservamos uma compreensão melhor articulada e alinhada ao entendimento de Paula (2014)

Você analisa e a partir disso você cria mediações para você intervir naquele processo. Porque a gente sabe da contradição das relações sociais, não é contradição do Serviço Social, é a contradição das relações sociais. Então as estratégias são fundamentais para você tencionar esse processo, de você construir possibilidades na intervenção... (Entrevistado/a 15).

Eu acho que é aquilo que o profissional pensa analisando os limites e possibilidades de atuação que tem (Entrevistado/a 20).

Encontramos, também, o entendimento das estratégias como "os objetivos de médio a longo prazo que o assistente social estabelece na instituição de trabalho e na sua prática profissional" (Entrevistado/a 5). Vemos aqui a tratativa das estratégias como sinônimo de objetivos profissionais e, conforme apontamos, é importante compreender que elas se configuram como parte do processo necessário ao alcance dos objetivos, mas sem com eles se confundirem. Por outro lado, outros/as entrevistados/as demonstraram que as estratégias se constituem enquanto meios para se alcançar determinado objetivo:

Então, estratégias, eu acredito que sejam... os meios, né? Para você chegar ao seu objetivo (Entrevistado/a 09).

Temporalis, Brasília (DF), ano 19, n. 37, p. 188-204, jan./jun. 2019. | ISSN 2238-1856 
São as estratégias que o profissional usar para chegar em determinado objetivo (Entrevistado/a 11).

Encontramos, ainda, outras respostas permeadas pela discussão das dimensões da profissão. Em relação à articulação com a dimensão ético-política da profissão, algumas respostas vincularam a postura ética e política do/da profissional às estratégias, partindo da compreensão de que elas emergem e são norteadas pelo compromisso ético assumido pelos/as assistentes sociais, podendo oferecer um direcionamento ao exercício profissional.

Estratégias profissionais, eu enxergo elas como um posicionamento ético político do assistente social dentro do trabalho dele, dentro do campo que ele está inserido, sendo a estratégia qual for. Mas eu vejo o posicionalmente ético político através dessa estratégia, [...] e se existe uma estratégia [...] ela tem uma intencionalidade (Entrevistado/a 06).

Então, a estratégia gira em torno com o projeto ético-político. [...] gira em torno de uma compreensão ampla do trabalho do Serviço Social, dos desafios e do que nós queremos com ele. Qual o rumo que a gente vai dar para o trabalho que a gente tiver, que a gente tenha que exercer (Entrevistado/a 17).

Já no que tange à articulação com a dimensão técnico-operativa, apareceram elementos pertinentes ao debate da instrumentalidade do Serviço Social, embora de forma turva e sem definição clara do significado desta dimensão.

Contudo, não identificamos nas respostas nenhuma menção à dimensão teóricometodológica como um elemento também fundamental, pois, se as estratégias não são neutras, significa que estão pautadas em algum referencial teórico, ainda que o/a assistente social possa não ter consciência disso.

Já no que concerne, especificamente, às táticas, quando perguntados/as sobre seu significado, apareceram compreensões do conceito como sinônimo de estratégia, em que se deve destacar o teor de dúvida e questionamento presente nas respostas.

Táticas profissionais? Eu não entendo muito bem de táticas profissionais... esse termo? Porque táticas, para mim, e estratégias eram a mesma coisa. Então, eu não sei diferenciar táticas e estratégias profissionais (Entrevistado/a 03).

Táticas? Estratégias e táticas é mais ou menos a mesma coisa? Acho que é a mesma coisa (Entrevistado/a 08).

Táticas... eu não sei... seria a mesma coisa que estratégias? (Entrevistado/a 20).

Em outras respostas as táticas foram entendidas como um meio para alcance das estratégias.

As táticas seriam uma forma de complementação dessas estratégias, as táticas são as formas cotidianas de se alcançar essa estratégia profissional [...]. As táticas seriam como realizar, seriam como tornar concretos os elementos da intervenção profissional de realizar aquele objetivo específico (Entrevistado/a 05).

Eu não consigo descolar táticas de estratégias, para mim a tática ela é uma maneira como eu vou operar os degraus da minha estratégia (Entrevistado/a 06). 
Em relação à vinculação com as dimensões da profissão, as táticas foram mais relacionadas à dimensão técnico-operativa, especialmente, aos instrumentos. Segundo Paula (2016), é no momento técnico-operativo do trabalho profissional do/da assistente social que as táticas se constroem, embora sejam perpassadas pelas demais dimensões que compõem o Serviço Social.

São os instrumentos que a gente usa para chegar a um fim que é a garantia de direitos dos usuários ou o que quer que seja. (Entrevistado/a 01).

Quando perguntados/as se, em algum momento da formação foi realizado debate sobre a elaboração de estratégias e táticas profissionais, dezesseis alunos/as responderam sim e quatro alunos/as disseram que não.

Entre os/as que afirmaram que sim, oito alunos/as apontaram que esse debate ocorreu em, pelo menos, uma das disciplinas de Oficina de Trabalho Profissional, sendo que a Oficina I foi citada cinco vezes, a Oficina II foi mencionada uma vez e a Oficina III foi lembrada quatro vezes.

Outros espaços mencionados como lócus desse debate foram: os laboratórios de área de intervenção, totalizando três entrevistados/as; as oficinas de supervisão de estágio, somando dois entrevistados/as; em outras disciplinas (sem especificá-las), mas principalmente articulado à discussão sobre a autonomia relativa do assistente social, perfazendo dois entrevistados/as; e, ainda, a disciplina de classes e movimentos sociais foi mencionada por um/a entrevistado/a.

Outros/as alunos/as, por sua vez, apontaram que o debate em torno da construção de estratégias profissionais aconteceu em algum momento do curso, no entanto, a discussão acerca da elaboração de táticas profissionais não ocorreu, conforme demonstram os trechos abaixo:

Estratégias sim, táticas eu não me lembro (Entrevistado/a 07).

De estratégias sim, mas de tática eu não estou lembrada, por isso que eu não sei se é a mesma coisa porque eu acho que não é (Entrevistado/a 10).

Estratégias sim. Eu acho que durante a formação a gente debate bastante sobre estratégias profissionais. Táticas... durante o meu processo de formação eu não lembro de ter sido trabalhado (Entrevistado/a 20).

Entre os/as alunos/as que afirmaram não, dizendo que em nenhum momento da formação foi realizado debate sobre a elaboração de estratégias e táticas profissionais, foi perguntado quando/onde, eles/as avaliavam que seria mais pertinente inserir essa discussão. Frente a essa questão todos/as alunos/as sinalizaram que esse debate deveria ser realizado a partir da inserção em campo de estágio e que o melhor lugar para a alocação dessas reflexões seriam as disciplinas de Oficina de Trabalho Profissional.

Os/as participantes da pesquisa foram, ainda, perguntados/as sobre as possíveis estratégias e táticas a serem construídas por eles/as em sua futura atuação profissional. Diante dessa questão, dez entrevistados/as (50\%) apontaram que não seria possível defini- 
las previamente, pois essas precisam ser construídas para atender às necessidades de determinada demanda e/ou realidade e/ou instituição específica.

Destacamos, então, um elemento que se torna fundamental à elaboração de estratégias e táticas: a análise objetiva da realidade. Segundo Paula (2014), faz-se necessário identificar as condições reais que se apresentam ao profissional, ou seja, os limites, as dificuldades, as possibilidades, as potencialidades de determinada realidade onde serão desenvolvidas as suas ações. "Assim, se previamente são detectados os elementos presentes em determinada realidade, pode-se elaborar estratégias e táticas mais eficazes, que se aproximem mais de um resultado exitoso" (PAULA, 2014, p. 141).

A realidade onde se inserem os/as assistentes sociais encontra-se em constante movimentação, por isso, as estratégias e táticas de intervenção precisam acompanhar esse movimento. Com isso, percebemos que cada situação específica exige a elaboração de estratégias e táticas também particulares. Portanto, não existem fórmulas genéricas capazes de oferecer respostas iguais para situações que são diferentes (PAULA, 2014).

\footnotetext{
Entretanto, partindo dessa premissa, julgamos pertinente a reflexão em torno de possíveis orientações que possam - ou não - servir de estímulo aos profissionais no seu processo particular de construção de estratégias e táticas políticointerventivas. Lembrando que toda e qualquer orientação precisa ser pensada a partir de uma determinada realidade específica, podendo ser adaptada ou até mesmo descartada a depender da situação em que o profissional se encontra (PAULA, 2014, p. 483).
}

Nesse sentido, alguns/algumas aluno/as indicaram algumas possíveis estratégias e táticas que podem ser desenvolvidas em qualquer espaço sócio ocupacional do/da assistente social, a partir da avaliação desse profissional sobre as condições objetivas para isso. Foram destacados alguns procedimentos trabalhados ao longo da formação profissional - como a análise de conjuntura, a análise institucional, a elaboração de plano de trabalho e/ou projeto de intervenção - como importantes estratégias a serem construídas pelo/a assistente social.

Algumas entrevistas sinalizaram que as estratégias e táticas devem ter como norteadores as leis e documentos que regem essa profissão - como o Código de Ética e a Lei de Regulamentação. Ressaltaram, ainda, que elas devem ser construídas em consonância com o projeto de profissão a que se vincula o/a assistente social. E mencionaram elementos que compõem o projeto profissional crítico, hoje hegemônico no Serviço Social.

[...] acho que a estratégia, ela tem que sempre visar você ter um exercício profissional comprometido com o código de ética, atendendo à lei de regulamentação da profissão e também numa perspectiva de emancipação mesmo dos sujeitos, através da dimensão socioeducativa [...] (Entrevistado/a 03).

As referidas respostas revelam que os/as discentes têm compreensão sobre os elementos que envolvem o debate das estratégias e das táticas no campo do Serviço Social. Contudo, ainda não apresentam aprofundamento teórico sobre eles, posto que os indicam sem fazer as devidas articulações. 
Isto revela a importância de que este debate esteja mais presente nas ementas de graduação, principalmente nas disciplinas em que o viés operacional da profissão seja protagonista (PAULA, 2016).

\section{CONSIDERAÇÕES FINAIS}

A construção de estratégias e táticas político-interventivas sempre se realizou no exercício profissional dos/das assistentes sociais, desde o surgimento da profissão. No entanto, pouco se tem discutido sobre esse processo e pouco se tem produzido a respeito desse tema.

Talvez, pela carência desse debate, ainda hoje, muitos/as assistentes sociais incorram em ultrageneralizações procedimentais, com base em suas experiências empíricas (GUERRA, 2012). Esses/as profissionais pautam-se em uma determinada forma de captar a realidade e em determinada maneira de atuar sobre ela, generalizando a sua intervenção profissional através de experiências passadas que se tornam um "modelo" a ser seguido, válido para todas as futuras situações que se assemelhem àquela anterior.

Não é nesse sentido que defendermos a construção de táticas e de estratégias. Elas não podem se configurar como roteiros ou manuais práticos a serem seguidos de maneira indiscriminada. Assim, o único modo de se superar posturas profissionais ultrageneralizadoras é a apreensão dos processos sociais como totalidades dinâmicas “[...] que se compõem de vários aspectos e âmbitos e que apresentam diferentes níveis de complexidade" (FORTI; GUERRA, 2011, p. 3). E, segundo as mesmas autoras, a realização de uma leitura do real com esse nível de amplitude supõe a compreensão de teorias macroscópicas sobre a sociedade que nos permita uma análise dos elementos e dos nexos que compõem essa totalidade.

É desse modo que o conhecimento teórico-metodológico - e aqui estamos nos referindo especificamente à teoria marxista - coloca-se como elemento indispensável para a elaboração consciente e intencional de estratégias e táticas político-interventivas articuladas aos objetivos profissionais que se pretende alcançar. Lembrando que a elaboração das mesmas pode até facilitar, mas não assegura a plena realização desses objetivos.

Finalizando nossas reflexões - que de modo algum se esgotam ou se encerram nessas poucas linhas - reforçamos nossa defesa de que o debate em torno das estratégias e táticas se faz necessário no momento da formação profissional. Esses elementos apresentam-se como ferramentas importantes para os futuros assistentes sociais, pois, podem auxiliar na construção das ações desenvolvidas, bem como na definição dos seus objetivos de atuação, vinculados a um projeto de profissão efetivamente crítico.

Importantes não apenas no sentido pragmático de preparar profissionais para o mercado de trabalho, mas, principalmente, para que os/as futuros/as assistentes sociais estejam preparados para conhecer a profissão em toda sua complexidade (IAMAMOTO, 1992). Baseadas nesta importante consideração de lamamoto (1992), é que consideramos a presença dos conteúdos referentes ao debate das estratégias e das táticas como elemento indispensável ao ensino teórico prático, posto que com ele, o processo de formação pode

Temporalis, Brasília (DF), ano 19, n. 37, p. 188-204, jan./jun. 2019. | ISSN 2238-1856 
se qualificar de modo a preparar os/as discentes para uma intervenção que vá além das exigências imediatas do cotidiano, cada vez mais interpelado pelos processos de radicalização do capital.

\section{Referências}

BOGO, Ademar (org). Teoria da organização política III: escritos de Sun Tzu, Maquiavel, Clausewitz, Trotsky, Giap, Fidel Castro, Carlos Fonseca e Florestan Fernandes. São Paulo: Expressão Popular, 2008.

FALEIROS, Vicente de Paula. Estratégias em Serviço Social. São Paulo: Cortez, 1997.

FALEIROS, Vicente de Paula. Saber Profissional e Poder Institucional. São Paulo: Cortez, 1985.

FORTI, Valéria; GUERRA, Yolanda. “Na prática a teoria é outra?”. In: FORTI, V.; GUERRA. Serviço Social: temas, textos e contextos 2. ed. Rio de Janeiro: Lumen Juris, 2011. (Coletânea Nova de Serviço Social).

GUERRA, Yolanda. A dimensão técnico-operativa do exercício profissional. In: SANTOS, C. M.; BACKX, S.; GUERRA, Y. (org). A dimensão técnico-operativa no Serviço Social: desafios contemporâneos. Juiz de Fora: Editora UFJF, 2012.

IAMAMOTO, Marilda Villela. O Serviço Social na Contemporaneidade: trabalho e formação profissional. 5. ed. São Paulo: Cortez, 2001.

IAMAMOTO, Marilda Villela. Renovação e Conservadorismo no Serviço Social: ensaios críticos. São Paulo: Cortez, 1992.

NETTO, José Paulo. Teoria, método e história na formação profissional. Cadernos ABESS, São Paulo: Cortez, n. 1, 1986.

PAULA, Luciana Gonçalves Pereira de. Um debate sobre estratégias e táticas: problematizações no campo do Serviço Social. Rio de Janeiro: Universidade Federal do Rio de Janeiro, 2014.

PAULA, Luciana Gonçalves Pereira de. Estratégias e táticas: reflexões no campo do Serviço Social. 1. ed. Rio de Janeiro: Lumen Juris, 2016.

PINTO, C. C. G. Representações e Práticas do Empowerment nos trabalhos sociais. 2011. Tese (Doutorado em Ciências Sociais na Especialidade de Política Social)- Universidade Técnica de Lisboa, Lisboa, 2011. 
Luciana Gonçalves Pereira de Paula Autora do artigo e pesquisadora do Grupo de Estudos e Pesquisas dos Fundamentos do Serviço Social da Faculdade de Serviço Social/UFJF.

Assistente social. Professora Adjunta na Faculdade de Serviço Social da Universidade Federal de Juiz de Fora. Doutora em Serviço Social pelo Programa de Pós-Graduação da Escola de Serviço Social da Universidade Federal do Rio de Janeiro.

Nicole Cristina Oliveira Silva Autora do artigo e pesquisadora do Grupo de Estudos e Pesquisas dos Fundamentos do Serviço Social da Faculdade de Serviço Social/UFJF.

Assistente social. Professora Substituta na Faculdade de Serviço Social da Universidade Federal de Juiz de Fora. Mestra em Serviço Social pelo Programa de Pós-Graduação em Serviço Social da Universidade Federal de Juiz de Fora. 